\title{
Formação de agentes públicos municipais de esporte e lazer
}

\section{RESUMO}

O presente ensaio objetivou discutir a formação de agentes públicos municipais de esporte e lazer. Para tanto, discutimos criticamente a literatura produzida sobre gestão pública, gestores esportivos e formação em diálogo com as contribuições de Pierre Bourdieu acerca da educação e de Zarifian em relação ao conceito de competências. Debatemos como aspectos relevantes a serem considerados no processo de formação desses agentes: buscar a qualidade da gestão por meio da otimização dos recursos; preservar e dar utilidade aos recursos por meio do desenvolvimento sustentável; fomentar a participação popular; definir funções e responsabilidades frente aos objetivos propostos; ter domínio dos conhecimentos, técnicas e saberes próprios do esporte e do lazer e saber alinhá-los à realidade da comunidade; buscar a efetivação das políticas; refletir nas ações; desenvolver o princípio da formação política e social e o princípio do reconhecimento e da participação nos processo da gestão ampliada.

PALAVRAS-CHAVE: Formação; Gestão pública; Esporte; Lazer; Agentes
Andressa Pelói Bernabé

Doutoranda em Educação Física na

Universidade Estadual de Maringá Professora do Centro Universitário Uningá, Curso de Educação Física, Maringá, PR, Brasil andressa.bernabe@hotmail.com (ㄴ https://orcid.org/0000-0002-1636-5747

Fernando Augusto Starepravo Doutor em Educação Física

Universidade Estadual de Maringá, Departamento de Educação Física, Maringá, PR, Brasil

fernando.starepravo@hotmail.com https://orcid.org/0000-0002-1655-998X 


\title{
Professional qualification of municipal public sports and leisure agents
}

\begin{abstract}
This essay aims to discuss the training of municipal public sports and leisure agents. To this end, we critically discussed the literature produced on public management, sports managers and professional qualification in dialogue with the contributions of Pierre Bourdieu on education and Zarifian in relation to the concept of competencies. We discussed as relevant aspects to be considered in the process of professional qualification these agents: to seek the quality of management through the optimization of resources; preserve and use resources through sustainable development; promote popular participation; define roles and responsibilities in relation to the proposed objectives; mastering the knowledge, techniques and knowledge of sports and leisure and knowing how to align them with the reality of the community; seek the effectiveness of policies; reflect on actions; develop the principle of political and social formation and the principle of recognition and participation in the expanded management process.
\end{abstract}

KEYWORDS: Training; Public management; Sport; Leisure; Agents

Formación de agentes públicos municipales de deporte y ocio

\section{RESUMEN}

Este ensayo tiene como objetivo discutir la formación de los agentes públicos municipales de deporte y ocio. Para ello, discutimos críticamente la literatura producida sobre gestión pública, gestores deportivos y formación en diálogo con los aportes de Pierre Bourdieu sobre educación y Zarifian en relación al concepto de competencias. Discutimos como aspectos relevantes a considerar en el proceso de formación de estos agentes: buscar la calidad de la gestión a través de la optimización de recursos; preservar y utilizar los recursos a través del desarrollo sostenible; promover la participación popular; definir roles y responsabilidades en relación con los objetivos propuestos; dominar los conocimientos, técnicas y conocimientos del deporte y el ocio y saber alinearlos con la realidad de la comunidad; buscar la efectividad de las políticas; reflexionar sobre las acciones; Desarrollar el principio de formación política y social y el principio de reconocimiento y participación en el proceso de gestión ampliado.

PALABRAS-CLAVE: Formación; Gestión pública; Deporte; Ocio; Agentes 


\section{INTRODUÇÃO}

Desde a promulgação da Constituição da República Federativa do Brasil, em 1988, o esporte e o lazer foram instituídos como direitos, passando o Estado a responsabilizar-se pela oferta destes à toda população. Assim, substancialmente, tal responsabilidade recaiu a todos os entes federados, ou seja, União, estados e municípios.

Haja vista que a Constituição e a lei infraconstitucional referente ao esporte - a Lei Pelé não estabelecem as atribuições dos estados e dos municípios em relação à oferta do esporte e lazer à população, entende-se que a legislação apenas conferiu a essas instâncias do poder público, autonomia em relação à constituição de seus próprios sistemas de esporte e lazer. Portanto, essa instituição de imediato não acarretou mudanças profundas, de modo que fossem reconhecidos como direitos sociais amplamente difundidos na sociedade.

Frente ao complexo contexto do Estado brasileiro responsável pela garantia do acesso ao esporte e ao lazer por meio de políticas públicas, que se constituem de maneira autônoma em estados e municípios, e que apresentam múltiplas configurações decorrentes dos diferentes orçamentos, arranjos políticos e configurações estabelecidas, os agentes públicos que elaboram e implementam políticas públicas de esporte e lazer merecem destaque. Os agentes são entendidos como sujeitos primordiais na efetivação e gestão das políticas públicas de esporte e lazer, uma vez que atuam decisivamente na arena política e desenvolvem os programas, os projetos e as ações de esporte e lazer na sociedade.

Neste estudo, especificamente, o foco volta-se ao contexto municipal de desenvolvimento do esporte e lazer como direitos sociais. Portanto, os agentes públicos são entendidos aqui como os principais sujeitos responsáveis pela gestão pública do esporte e lazer no contexto municipal.

Ao nos pautarmos nos preceitos da Teoria dos Campos de Pierre Bourdieu, entendemos os agentes como sujeitos de ação que podem modificar ou manter as estruturas sociais existentes. Na realidade social de nosso país, os agentes são entendidos como aqueles que atuam em entidades voltadas ao desenvolvimento de políticas públicas e oferta do esporte e lazer à população, seja na Secretaria Especial do Esporte, em âmbito federal, ou nas secretarias e órgãos estaduais ou municipais ligados ao esporte e lazer. Para o escopo de análise do nosso estudo, consideramos os agentes púbicos do esporte e lazer atuantes no âmbito municipal, sendo eles professores, estagiários, profissionais técnicos e gestores (secretário ou diretor responsável pelo órgão público municipal voltado ao esporte e lazer). 
Entendidos como sujeitos que podem modificar ou manter as estruturas sociais existentes, as ações dos agentes públicos no âmbito da gestão pública podem abrir caminhos de mudança frente ao maior reconhecimento e difusão do esporte e do lazer como direitos em nosso país. Araújo et al. (2007), por exemplo, afirmam que o baixo nível de escolaridade e a falta de formação adequada, relacionados ao capital cultural e social que o agente possui, têm reflexo direto na qualidade das ações de esporte e lazer ofertadas pelos agentes públicos do esporte e lazer. Mezzadri et al. (2006) também afirmam a importância e necessidade de se discutir e investir na formação dos agentes públicos por entenderem que: “é fundamental termos um aumento da quantidade e da qualidade dos profissionais que trabalham na área. A sua melhora qualitativa pode se dar, por exemplo, através de programas permanentes de capacitação" (s/p).

A partir dessa contextualização, consideramos que a formação dos agentes pode ser um aspecto crucial na gestão pública do esporte e lazer. É importante ressaltar que, a princípio, consideramos que a formação não diz respeito apenas ao nível de escolaridade dos agentes. A formação a que nos referimos caracteriza-se como um processo constante, tanto no sentido formal, a partir de cursos de graduação e pós-graduação, quanto em sentido diário, a partir da participação em cursos, capacitações, palestras, reuniões, conversas com outros agentes e outros meios de troca de experiências.

Frente a tais considerações e imersos no universo da gestão pública municipal, objetivamos com este ensaio discutir a formação de agentes públicos municipais de esporte e lazer.

Para argumentar frente a formação de agentes públicos municipais de esporte e lazer, discutimos criticamente a literatura produzida sobre gestão pública, gestores esportivos e formação em diálogo com as contribuições de Pierre Bourdieu acerca da educação e de Zarifian em relação ao conceito de competências, a fim de estabelecer novos nexos explicativos sobre a formação de agentes públicos de esporte e lazer. De forma complementar utilizamos dados do Ministério da Educação (MEC), por meio do Sistema e-MEC(http://portal.mec.gov.br), a fim de contextualizar os cursos de formação em gestão esportiva e de lazer.

\section{Reflexões sobre a formação de agentes públicos municipais de esporte e lazer}

Entendemos que se faz necessário reconhecer e valorizar a atuação dos agentes públicos, pois são estes os principais responsáveis pela oferta do esporte e lazer à população, principalmente em relação à realidade municipal, levando-se em consideração que, inúmeras características e condições estruturais, interferem na gestão pública municipal. A consulta à produção científica 
sobre gestão pública de esporte e lazer apontam algumas características e condições estruturais, dentre elas, os baixos orçamentos e investimentos na área do esporte e lazer, a insuficiência ou precariedade dos recursos físicos e materiais, e outros fatores que podem impedir ou dificultar a ação dos agentes públicos (ARAÚJO et al., 2007; AMARAL; KIKUCHI, 2011; GALINDO, 2005; GRUNENNVALDT et al., 2014; MARCELLINO et al., 2007; MARIN et al., 2009; MENDES et al., 2010; MENEZES; OLIVEIRA; SOUZA, 2012).

Autores como Werneck (1998) e Marcellino (2001) consideram que a formação deve ser pautada em uma fundamentação teórico-prática que integre diferentes saberes, experiências e conhecimentos. A formação pautada em uma fundamentação teórico-prática, segundo os autores, pode levar os agentes a assumirem uma postura reflexiva frente aos processos e contradições do meio em que estão inseridos.

Quando falamos em formação, a primeira questão comumente levantada é a escolaridade. O fato de possuir um certificado ou diploma que comprove a escolarização é reconhecido socialmente como um aspecto qualificador do agente. Em relação a essa naturalização de hierarquias mediante diplomas, Bourdieu (2007b, p. 307) discorre que:

A correspondência entre saberes hierarquizados (de maneira mais ou menos arbitrária, segundo as áreas e as disciplinas) e os diplomas, por sua vez, hierarquizados faz com que a posse, por exemplo, do diploma escolar mais elevado garanta, supostamente, por implicação, a posse de todos os conhecimentos garantidos pelos títulos de nível inferior ou, ainda, faz com que dois indivíduos no exercício da mesma função e dotados das mesmas competências úteis, ou seja, diretamente necessárias para o exercício de suas funções, apesar de providos de diplomas diferentes, tenham rodas as oportunidades de estar separados por uma diferença de estatuto (e, e claro, de tratamento): tudo isso em nome da idéia segundo a qual a competência outorgada pelos diplomas mais elevados pode garantir, por si só, o acesso aos conhecimentos - as "bases" - que se encontram na origem de todos os saberes chamados práticos ou aplicados.

A constatação dessa naturalização de hierarquias mediante diplomas é um dos pontos levantados por Bourdieu quando analisa os processos de escolarização, sendo esta uma de suas maiores contribuições para a educação. Quando falamos de escolarização ou sistema escolar, Bourdieu apresenta, em algumas de suas publicações, reflexões relacionadas a esse tema (BOURDIEU, 1999; BOURDIEU, 2006; BOURDIEU, 2008), que passaremos a discutir a seguir.

A escola é vista como uma instituição que transmite conhecimentos de forma democrática a todos os alunos. Bourdieu (2007a) considera que, da necessidade de resolução do problema de acesso à educação, emerge a proposição da escola pública garantir educação pública e gratuita a todos os cidadãos. Desta forma, a escola seria uma instituição neutra, baseada nos princípios de igualdade, oportunidades, meritocracia e justiça social, que difundiria o conhecimento e selecionaria 
seus alunos a partir de critérios racionais. Bourdieu (2007a, p. 41), entretanto, contrapõe essa lógica, pois ao invés desses princípios visualiza outra interpretação da escola e da educação pelo viés da reprodução e legitimação das desigualdades:

É provavelmente por um efeito de inércia cultural que continuamos tomando o sistema escolar como um fator de mobilidade social, segundo a ideologia da "escola libertadora", quando, ao contrário, tudo tende a mostrar que ela é um dos fatores mais eficientes de conservação social, pois fornece a aparência de legitimidade às desigualdades sociais, e sanciona a herança cultural e o dom social tratado como dom natural.

Podemos observar que Bourdieu (2007a) refuta a ideia da escola como um meio de garantir “justiça social” e igualdade de oportunidades a todos pelo viés da meritocracia, quando percebe que o conhecimento não é transmitido igualmente para todos os alunos como a escola faz parecer. Para ele, alunos de classes favorecidas trazem de berço uma herança, o capital cultural, que os torna mais propensos a absorver a cultura escolar.

A cultura consagrada e transmitida pela escola é socialmente reconhecida como cultura legítima, universalmente válida. Essa cultura escolar, para Bourdieu (2007a), seria a cultura imposta pelas classes dominantes como legítima. A essa dinâmica, denominou de "arbitrário cultural dominante", quando uma cultura se impõe à outra. Sendo a cultura um elemento de dominação, as classes dominantes, além da imposição, atribuem um valor incontestável a ela.

Bourdieu (2007a), transpondo essa ideia para dentro da escola, admite que esta instituição, dissimuladamente, contribui para que a cultura, tida como legítima, seja transmitida favorecendo alguns alunos em detrimento de outros. Os desfavorecidos são aqueles que não tiveram contato ou acesso, a partir da família, a capitais culturais objetivados na forma de livros e obras de arte, por exemplo, como também outras formas simbólicas de capital cultural. Esses alunos não conseguem dominar os mesmos códigos culturais que a escola valoriza. O aprendizado, para eles, pode se tornar muito mais difícil. Em relação ao capital cultural transmitido pela família, Bourdieu (2007a, p. 41-2) afirma:

[...] cada família transmite a seus filhos, mais por vias indiretas do que diretas, um certo capital cultural e um certo ethos, sistema de valores implícitos e profundamente interiorizados, que contribui para definir, entre coisas, as atitudes face ao capital cultural e à instituição escolar. A herança cultural, que define, sob os dois aspectos, segundo as classes sociais, é a responsável pela diferença inicial das crianças diante da experiência escolar e, consequentemente, pelas taxas de êxito.

Bourdieu entende que, assim, a escola marginaliza esses alunos, enquanto privilegia os dotados de capital cultural. Por isso contrapõe o discurso de igualdade que a escola prega. Um 
exemplo dessa dominação cultural nas escolas é a escolha das matérias tidas como mais relevantes. Não é difícil perceber que nos currículos, disciplinas como física, matemática e história são mais valorizadas do que disciplinas como arte e educação física.

Uma vez reconhecida como legítima e portadora de um discurso neutro, a escola exerce suas funções de reprodução e legitimação das desigualdades sociais, livre de qualquer suspeita. Nessa lógica, as posições prestigiadas e elevadas - definidas em termos de ramos de ensino, disciplinas, e estabelecimentos - no sistema de ensino tendem a ser ocupadas por agentes pertencentes aos grupos socialmente dominantes. Para Bourdieu, essa lógica não é obviamente causal e nem pode ser explicada exclusivamente pelas diferenças objetivas, sobretudo as econômicas. Para ele, essa lógica só pode ser explicada quando consideramos que a escola, de modo dissimulado, valoriza e exige dos alunos determinadas "qualidades", que são desproporcionalmente distribuídas, as quais são constituídas por meio do capital cultural e que estabelecem certa naturalidade no trato com a cultura e o saber que só aqueles que foram socializados desde a infância pela cultura legítima possuem. $\mathrm{O}$ trecho a seguir, extraído dos escritos de Bourdieu (2007a, p. 42), afirma essa lógica:

Paul Clerc mostrou que, com diploma igual, a renda não exerce nenhuma influência própria sobre o êxito escolar e que, ao contrário, com renda igual, a proporção de bons alunos varia de maneira significativa segundo o pai não seja diplomado ou seja bachelier* (N.T.: No sistema francês, pessoa que concluiu com sucesso seus estudos secundários e tornou-se, portanto, portadora do "baccalauréat" (ou, na forma abreviada, "bac"), cuja tradução literal, em português, seria "bacharelado", mas que, em francês, designa, ao mesmo tempo, os exames e o diploma conferido ao final do $2^{\circ}$ ciclo de ensino de $2^{\circ}$ grau), o que permite concluir que a ação do meio familiar sobre o êxito escolar é quase exclusivamente cultural. Mais que os diplomas obtidos pelo pai, mais mesmo do que o tipo de escolaridade que ele seguiu, é o nível cultural global do grupo familiar que mantém a relação mais estreita com o êxito escolar da criança.

Partindo de tais contribuições de Bourdieu para o entendimento do universo escolar e do saber, entendemos que somente nos pautar na escolaridade do agente público para identificarmos e analisarmos sua formação seria um tanto quanto limitado. Por esse motivo, consideramos a formação como um processo amplo, que considera não apenas a escolaridade dos agentes, mas também, a formação em seu sentido constante, segundo o aspecto da continuidade. Consideramos essa formação de sentido constante ou continuada como aquela que é desenvolvida no dia a dia, por meio da reflexão-ação que embasa a prática diária dos agentes, seja a partir da busca constante por novos conhecimentos, seja por meio de cursos, palestras e trocas de experiências, por meio de estratégias em que se busca aprender, ensinar e refletir a partir das ações desenvolvidas.

Entendemos que todos esses pontos podem ser considerados quando pensamos na formação de agentes que atuam na gestão do esporte e lazer nos municípios. Porém, como afirmamos 
anteriormente, autores como Werneck (1998) e Marcellino (2001) enfatizam que essa formação deve ser pautada em uma fundamentação teórico-prática, de modo que possa ter reflexo nas tomadas de decisões e ações dos agentes frente às contradições e processos que compõem a gestão pública do esporte e lazer. Pensando em todos esses pontos levantados, questionamos: é possível definir características, especificidades, competências e peculiaridades inerentes à formação dos agentes públicos que atuam na gestão do esporte e lazer?

Discutir a respeito da formação de agentes públicos que atuam na gestão pública do esporte e lazer no Brasil é um tanto quanto complexo. Autores como Amaral e Bastos (2015) afirmam que essa complexidade se dá devido ao fato de não haver uma área ou curso específico que consiga subsidiar sozinho esta formação em nosso país. Tavares $(2010$, p. 47) afirma que acaba sendo atribuído principalmente aos cursos de Administração e Educação Física "a tarefa de atender à complexa demanda da gestão pública esportiva". É por esse motivo que Werneck (1998) e Marcellino (2001)alegam, baseando-se em estudos que discutem a formação de gestores do esporte que atuam em nosso país, que é comum encontrar formação diferenciada entre gestores que ocupam cargos semelhantes.

Aqui, porém, fazemos uma ressalva: será que um determinado curso ou área seria capaz de subsidiar a formação e atuação dos agentes públicos do esporte e lazer? Refletindo acerca dos apontamentos de Bourdieu (2007a; 2007b) a respeito do universo escolar e processo de escolarização, entendemos que os mesmos limitantes da escola - como reprodução de uma determinada cultura, marginalização de alguns alunos em detrimento do privilégio aos "mais aptos" - podem estar presentes nos cursos superiores.

Mazzei e Bastos (2012), ao discorrerem acerca da formação em Gestão do Esporte, afirmam que a formação dos gestores esportivos em nosso país geralmente é desenvolvida por meio de Cursos de Graduação em Educação Física ou Esporte. Mas, ponderam que outras alternativas de cursos surgiram nos últimos anos na realidade brasileira, como exemplos, a criação do Curso de Bacharelado em Gestão Desportiva e do Lazer em 2009 na Universidade Federal do Paraná Campus do Litoral (Matinhos - PR.); Curso de Bacharelado em Educação Física com ênfase em Gestão do Esporte e Lazer; e cursos técnicos e profissionalizantes em Gestão do Esporte - cursos com duração de 2 anos voltados à formação de Tecnólogo.

Ao realizarmos a busca por cursos de Gestão Desportiva e de Lazer cadastrados no Ministério da Educação (MEC), por meio do Sistema e-MEC, encontramos um total de 52 cursos cadastrados em todo país. Dos 52 cursos cadastrados, 51 são cursos ofertados em caráter tecnológico e apenas 1 é um curso de graduação em bacharelado. Este único Curso de Bacharelado em Gestão Desportiva e do Lazer em caráter de graduação da UFPR-Campus do Litoral ofertou o 
último vestibular no ano de 2014 e posteriormente entrou em processo de extinção. No ano de 2015, o curso possuía apenas alunos remanescentes das últimas turmas. Segundo informações de professores que ministravam aulas no curso, o processo de extinção ocorreu devido à baixa procura e baixo reconhecimento no mercado de trabalho, pois a maioria dos concursos e processos de seleção acabam dando prioridade a profissionais com graduação em Educação Física para assumir cargos na gestão do esporte e lazer. Tais fatores acabaram sendo exacerbados devido ao fato de o curso ser ofertado em uma cidade pequena.

Se classificarmos os cursos por regiões brasileiras, verificamos, na região Norte, 5 cursos ativos, sendo que todos eles são tecnológicos; na região Nordeste 10 cursos, todos tecnológicos; na região Centro-Oeste são ofertados 6 cursos, todos em caráter tecnológico; na região Sudeste, 21 cursos ofertados também tecnológicos; e, na região Sul, dos 7 cursos ofertados, 1 era bacharelado, mas, como afirmado anteriormente, entrou em processo de extinção, e os demais são tecnológicos.

Em relação à nomenclatura, apenas um dos cursos ofertados no estado do Ceará é intitulado "Gestão do esporte e lazer comunitário", todos os demais intitulam-se "Gestão desportiva e de lazer". Portanto, podemos constatar, com base nos dados apresentados na Tabela 1, a homogeneidade na maioria dos cursos quanto ao tipo e nomenclatura. O caráter técnico, de curta duração, é o que sobressai quando consideramos a oferta de cursos voltados à gestão do esporte e lazer em nosso país.

Nossas constatações vão ao encontro de Mazzei e Bastos (2012) quando afirmam que, no Brasil, têm surgido alternativas para a formação em gestão do esporte e lazer, como o curso Bacharelado em Gestão Desportiva e do Lazer da UFPR Campus do Litoral, além de cursos técnicos e profissionalizantes. Os autores alegam a falta de cursos de pós-graduação stricto sensu que tratem especificamente da gestão esportiva em nosso país, afirmando que existe apenas linhas de pesquisa em cursos de mestrado, geralmente em Educação Física (MAZZEI; BASTOS, 2012).

A partir desse cenário, os autores apontam que uma das grandes dificuldades dos escassos cursos que existem em nosso país é a falta de consenso sobre quais seriam as disciplinas ou conhecimentos comuns a área. Mas, mesmo com as diferenças nas estruturas curriculares dos cursos, os autores ressaltam que algumas disciplinas são comuns à maioria dos programas, como:

Marketing esportivo; Finanças e Contabilidade; Planejamento Estratégico; Comunicação, Administração e Políticas Públicas; Aspectos Legais e Direito do Esporte; Economia; Dimensões Sociais, Culturais e Antropológicas do Esporte; Ética nas Organizações, e Liderança e Motivação no Esporte (MAZZEI; BASTOS, 2012, p. 35). 
Considerando o levantamento realizado e as discussões de Mazzei e Bastos (2012), mesmo sendo escassa a oferta de cursos técnicos, de graduação ou de pós-graduação em gestão do esporte e lazer, estes apresentam-se como uma das possibilidades quando pensamos em processos de formação daqueles que atuam ou atuarão na gestão do esporte e lazer, seja em meios públicos ou privados. Mesmo afirmando ser uma das possibilidades, não representa o único meio de formação de agentes públicos do esporte e lazer. Assim afirmamos, pois, como havíamos mencionado anteriormente, entendemos que a formação a que nos referimos, refere-se à uma formação constante e não estável, desenvolvida somente por um certo período de tempo e geralmente em uma fase da vida antes de assumirem cargos na gestão do esporte e lazer. Por pautar-se em um sentido constante e continuado, entendemos que esta formação deva basear e ser buscada constantemente no decorrer da atuação dos agentes.

Assim, concordamos com Tavares (2010) quando afirma que a formação para atuar na gestão pública pode ser obtida por meio do acúmulo de diferentes cursos e experiência em diferentes situações. Essas duas frentes podem representar um caminho para se desenvolver um perfil de competências que o cargo na gestão pública do esporte e lazer pode exigir. Mas, quais são as competências que os agentes públicos devem possuir para atuarem na gestão pública do esporte e lazer? É possível elencar competências necessárias à essa atuação? Os gestores públicos possuem competências inerentes ao cargo que assumem?

Antes de buscar elementos para responder aos questionamentos suscitados, ressaltamos que o gestor - aqui considerado na figura do secretário ou agente maior responsável pelo esporte e lazer nos municípios analisados - é apenas um elemento diante da complexidade da gestão pública. Como afirma Tavares (2010), frente essa complexidade, torna-se de suma importância reconhecer a figura de outros agentes, ou nas palavras do autor "componentes" que fazem parte dessa realidade social. Para exemplificar tal importância, o autor assegura que uma equipe qualificada pode auxiliar o gestor de modo que uma equipe menos qualificada não proporcionaria ${ }^{21}$. É por esse motivo que optamos por debater a formação, tanto dos gestores quanto dos professores, estagiários ou profissionais técnicos que atuam em secretarias ou órgãos públicos responsáveis pela oferta do esporte e lazer. Tanto os gestores quanto os professores, técnicos e estagiários são, por nós considerados, agentes públicos do esporte e lazer.

Quando falamos em um perfil de competências que a atuação dos agentes públicos na gestão do esporte e lazer pode exigir, consideramos que a manifestação desses agentes é construída e ambientada no tempo histórico e cultural e a partir dos traços de personalidade individuais de cada agente. Portanto, quando optamos em discutir a respeito de um perfil de competências é relevante 
ressaltarmos que esse perfil é oriundo desse processo de construção, "fruto da interatividade entre as características ambientais e pessoais" (TAVARES, 2010, p. 19).

$\mathrm{Na}$ literatura encontramos algumas discussões voltadas ahabilidades ou competências inerentes à atuação do gestor esportivo (TAVARES, 2010; MAZZEI; BASTOS, 2012; AMARAL; BASTOS, 2015), relacionada principalmente à área da Gestão do Esporte e produzida, sobretudo, por pesquisadores do GEPAE-EEFEUSP (Grupo de Estudos e Pesquisa em Gestão do Esporte Escola de Educação Física e Esporte da Universidade de São Paulo). Porém, devemos entender que discussões, tais como estas, mostram possibilidades e não modelos estáveis de competências, pois estamos nos referindo a um processo complexo, principalmente quando consideramos as especificidades da gestão pública. A partir dessa ressalva, passaremos a apresentar modelos de competências presentes na literatura.

Ao discorrer sobre o conceito de competência, Zarifian (2001) afirma que o conceito deve ser pensado levando em consideração o indivíduo e não a qualificação de um emprego ou cargo definido. Assim, quando assumimos a necessidade de discutir competências inerentes à atuação dos agentes públicos, entendemos como preconiza Zarifian (2001, p. 67), que a competência se manifesta na relação prática dos agentes com sua situação profissional, no modo como enfrentam as situações peculiares ao cargo que ocupam. “[...] a competência só se manifesta na atividade prática, é dessa atividade que poderá decorrer a avaliação das competências nela utilizadas".

Zarifian (2001) ressalva que o entendimento de competência não se volta apenas à individualidade do sujeito, apontando-o como principal ou único responsável por condições de competência. Faz-se necessário levar em consideração as condições presentes nas redes de trabalho e que as competências se apoiam em conhecimentos, corpos de saberes, como afirma:

Ora, esses conhecimentos formam-se socialmente e, se quisermos escapar de uma validação absolutamente momentânea (tal indivíduo é competente tal dia diante de tal situação), o êxito das ações deve remeter a uma dialética de interdependência forte entre competências e conhecimentos, mobilizada por fontes e atores diferentes (por mais que a empresa seja o local em que se utiliza competência ela não é, de longe, o único local de sua produção) (ZARIFIAN, 2001, p. 68).

Para o autor, a competência só pode ser entendida e avaliada mediante situações e que, pode, em partes, ser expressa e se desenvolver na relação com a situação, mas que certos fatores podem interferir nessa relação (ZARIFIAN, 2003). O conhecimento social, conceito de Norbert Elias (2002), é um dos fatores que intervém na relação entre situação e competência. É entendido como todo conhecimento que é construído no decorrer da trajetória histórica e social de um indivíduo em uma determinada sociedade. Assim, pode ser considerado como o conjunto de conhecimentos que ajuda os indivíduos a se orientarem. Nas palavras do autor "esse conhecimento social se 
particulariza naquilo em que um indivíduo pode dele apropriar-se ao longo de sua trajetória de socialização, e na maneira como ele questiona e renova esse conhecimento" (ZARIFIAN, 2003, p. 153). Por esse motivo, o autor entende que as condições da competência de um indivíduo são constituídas muito além das situações enfrentadas: “Em uma ampla medida, essas situações já são o produto desse conhecimento e não podem ser entendidas independentes dele" (ZARIFIAN, 2003, p. $153)$

Outro fator que interfere nas condições da competência é a "inteligência prática" (ZARIFIAN, 2003). Segundo o autor, o núcleo dessa inteligência é a compreensão das situações, compreensão na qual os conhecimentos são mobilizados. Desta forma, utilizamos a inteligência prática para compreender determinadas situações, sendo que só podemos compreendê-las a partir da mobilização do conhecimento social (ZARIFIAN, 2003).

Por todos esses pontos discutidos, Zarifian (2001) afirma a necessidade de se considerar a multiplicidade e a interação das mais diversas competências profissionais em seus contextos de inserção. Nesse sentido, apropriamo-nos das palavras do autor para definir o conceito de competência como a tomada de iniciativa e o assumir responsabilidades mediante problemas e eventos enfrentados em situações profissionais. Pelo fato de não ser um conceito entendido somente no plano individual, é também entendido como a faculdade de mobilizar agentes em uma determinada situação, compartilhando desafios e assumindo responsabilidades. É, portanto “[...] uma inteligência prática das situações, que se apoia em conhecimentos adquiridos e os transforma à medida que a diversidade das situações aumenta" (ZARIFIAN, 2003, p. 137).

Mesmo que o modelo de gestão por competências baseie-se na aproximação entre trabalho e trabalhador, tornando as situações que ocorrem nesse contexto um importante elemento para o desenvolvimento das competências, esse modelo afirma a necessidade de o agente estar devidamente preparado a partir dos plenos domínios de seus saberes e o entendimento de como dar-lhes sentido em sua atuação diária para desempenhar as funções relativas ao cargo que exerce (ZARIFIAN, 2001).

Para que esse modelo de gestão por competências seja sustentável, entendemos, como afirma Tavares (2010), que é necessário um levantamento das competências que são essenciais ao cargo em questão, inclusive para a construção de um perfil profissional adequado ao cargo. Mas, para não nos limitarmos à ideia de enrijecimento do fazer profissional é necessário considerar que as relações de trabalho não são estáticas. Eventos e situações podem ocorrer de modo inesperado, desregulando a normalidade do sistema, o que requer do agente competências diferenciadas ou agregadas frente à mobilização dos mais variados recursos para a resolução das tarefas e demandas impostas pelo trabalho (TAVARES, 2010). 
A partir dessas considerações, podemos pensar no seguinte questionamento: mas, como se dá o processo de desenvolvimento das competências? Tavares (2010, p. 22) afirma que esse entendimento de competência baseado no modelo de gestão por competência "só se sustenta a partir de um contínuo processo de formação, uma vez que a busca pelo desenvolvimento e pela mudança é o processo central desse modelo". Portanto, baseando-nos no entendimento dos autores, podemos afirmar que o processo de desenvolvimento das competências irá depender da pretensão dos agentes e a busca por um contínuo processo de formação seja por interesse próprio, seja por parte dos órgãos responsáveis em ofertar políticas, meios ou possibilidades de formação. Por possuir essa relação direta com a formação, que nos pautamos nessa conceituação do termo competência para nortear nossas discussões.

Na literatura brasileira, Fleury e Fleury (2011), baseando-se nas obras do francês Zarifian, apresentam um quadro onde demonstram como a noção de competência pode ser desenvolvida a partir de sete verbos e as ações que eles estabelecem, como pode ser verificado no Quadro 1:

Quadro 1 - Competências do profissional

\begin{tabular}{|c|c|}
\hline \multicolumn{2}{|c|}{ Ações que constituem o conceito de competência } \\
\hline Verbos & Ações \\
\hline Saber agir & $\begin{array}{ll}- & \text { Saber o que e por que faz } \\
- & \text { Saber julgar, escolher e decidir }\end{array}$ \\
\hline Saber mobilizar & $\begin{array}{l}\text { - Saber mobilizar recursos de pessoas, financeiros e } \\
\text { materiais de forma sinérgica }\end{array}$ \\
\hline Saber comunicar & $\begin{array}{l}\text { - Compreender, processar, transmitir informações e } \\
\text { conhecimentos, assegurando o entendimento da mensagem } \\
\text { pelos outros }\end{array}$ \\
\hline Saber aprender & $\begin{array}{ll}- & \text { Trabalhar o conhecimento e a experiência } \\
- & \text { Rever modelos mentais } \\
\text { - } & \text { Saber desenvolver-se e propiciar o desenvolvimento dos } \\
\text { outros } & \end{array}$ \\
\hline Saber se comprometer & $\begin{array}{l}\text { - Saber engajar-se e comprometer-se com os objetivos da } \\
\text { organização }\end{array}$ \\
\hline $\begin{array}{l}\text { Saber assumir } \\
\text { responsabilidades }\end{array}$ & $\begin{array}{l}\text { - Ser responsável, assumindo os riscos e as consequências } \\
\text { de suas ações e ser, por isso, reconhecido }\end{array}$ \\
\hline Ter visão estratégica & $\begin{array}{l}\text { - Conhecer e entender do negócio da organização, seu } \\
\text { ambiente, identificando oportunidades e alternativas }\end{array}$ \\
\hline
\end{tabular}

Fonte: Fleury e Fleury (2011, p. 31)

A partir do Quadro 1 podemos verificar ações relativas ao conceito de competências. Mesmo não sendo ações pensadas diretamente ao âmbito público, entendemos que são indicadores para pensarmos em competências essenciais aos agentes públicos. Saber agir, saber mobilizar, saber 
comunicar, saber aprender, saber comprometer-se, saber assumir responsabilidades e ter visão estratégica são ações amplas consideradas em um contexto geral que ao nosso ver, podem propor competências frente à função que os agentes assumem no âmbito público independente da área específica ou do cargo em que atuam. As ações indicadas no Quadro 1, podem ser direcionadas a uma determinada área como, por exemplo, a do esporte e lazer, bem como a um determinado cargo. Porém, mesmo apontando a importância de tais aspectos quando refletimos acerca das competências dos agentes públicos, é importante ressaltar que não desconsideramos outros elementos ou competências que podem advir do senso prático, das experiências diárias que ocorrem ou podem ocorrer na gestão pública municipal do esporte e lazer.

Podemos constatar que, de certo modo, as ações indicadas no Quadro 1 podem refletir competências ligadas a princípios de racionalidade técnica pois, como afirmam Soriano e Winterstein (2006), refletem medidas universalizadas e padrões a serem seguidos encobertos por habilidades gerais e referências à condutas ideais. Ainda segundo os autores, devemos ter cautela em assumir somente como verdade tais parâmetros desconsiderando outras habilidades ou competências que não aquelas colocadas como referências(SORIANO; WINTERSTEIN, 2006). Portanto, assumimos que as ações indicadas no Quadro 1 podem refletir certas competências ligadas a função que os agentes públicos exercem, mas entendemos que outras competências podem ser consideradas como aquelas advindas do senso prático, como por exemplo o saber ético, agir de forma ética mediante dificuldades ou situações peculiares que podem ocorrer no dia a dia nos municípios.

Ao discutir a respeito da Gestão do Esporte, Mazzei e Bastos (2012) afirmam que alguns autores, como Mintzberg (2003) tem se dedicado a analisar a intervenção profissional nessa área a partir do papel que o agente assume, no caso do modelo proposto por este autor, seja ele presidente considerado como "Vértice Estratégico", ou gerente considerado "Centro Operacional" de uma determinada organização. Em nosso caso podemos considerar os gestores como "Vértice Estratégico", e os professores, estagiários ou profissionais técnicos como "Centro Operacional".

O Centro Operacional, um dos componentes do Modelo de Estrutura Organizacional proposto por Mintzberg, pode ser entendido como uma estrutura que compreende todos os membros que operam e executam as ações de uma determinada organização, em nosso caso, os professores e técnicos que operam e executam as ações de esporte e lazer nos municípios(MAZZEI;BASTOS, 2012). Essa estrutura é entendida, portanto, como o "âmago de cada gestão", "parte crucial, que produz resultados essenciais" (MAZZEI; BASTOS, 2012, p. 85). Já o Vértice Estratégico, é aquele em que o(s) membro(s) responsável(eis) pelo controle da organização deve(m) assegurar a manutenção, o cumprimento e o desenvolvimento de estratégias apropriadas para se atingir os 
objetivos propostos, função que, em nosso entendimento, o agente assume quando está no posto de uma determinada secretaria ou órgão responsável pela oferta do esporte e lazer em seu município (MAZZEI; BASTOS, 2012).

Em relação às competências, características e peculiaridades do papel que o gestor desempenha, há estudos na literatura internacional que se voltam à análise de competências de gestores esportivos (TAVARES, 2010). Já, no Brasil, por serem recentes os estudos no campo das competências, suas ramificações, como a do esporte, são pouco expressivas. Mas, em relação à literatura internacional, Tavares (2010) aponta o estudo de Jamieson (1987) que investigou as competências de gestores esportivos americanos, alegando que as mais requeridas eram as competências decisórias, de planejamento, de controle orçamentário e de comunicação.

Joaquim, Batista e Carvalho (2011) realizaram uma revisão sistemática de estudos e pesquisas - artigos, teses e dissertações desenvolvidos em vários países entre 1980 e 2009 - sobre o perfil de competências do gestor esportivo a partir de bases de dados eletrônicas. Dentre os estudos encontrados, as autoras afirmam que os estudos internacionais, publicados em periódicos científicos, apontaram como competências mais importantes no trabalho de gestores esportivos aquelas de planejamento, de relações públicas, de marketing, de processos de liderança e de tomada de decisão. Já as teses e dissertações reforçaram o conhecimento na área do esporte, a comunicação e a gestão das relações interpessoais como competências mais importantes dos gestores esportivos analisados. De modo geral, as autoras apontam que, a partir das investigações, as competências mais valorizadas são as relacionadas ao planejamento de atividades, projetos e eventos; gestão de recursos seja eles humanos, financeiros, relacionados a instalações ou equipamentos; de liderança; de marketing; e de coordenação de equipes (JOAQUIM; BATISTA; CARVALHO, 2011).

Se compararmos o estudo de Jamieson (1987)com os apontamentos da revisão sistemática de Joaquim, Batista e Carvalho (2011), mesmo se tratando de épocas e nacionalidades diferentes, podemos verificar que ambos os estudos apresentam que as competências mais valorizadas ou mais requeridas ao gestor de esporte são relacionadas ao fato de saber planejar, tomar decisões, saber se comunicar e saber mobilizar, controlar ou coordenar recursos humanos e financeiros/orçamentários. Ao apresentarmos as competências a partir de verbos expressando ações, que seriam então competências valorizadas ou requeridas aos gestores esportivos como apontado pelos estudos, fazemos alusão aos verbos/ações (FLEURY; FLEURY, 2011) apresentados no Quadro 1. Assim, constatamos que, mesmo os autores se referirem a ações que constituem o conceito de competências profissionais de modo amplo sem se referirem a uma área específica, estas mesmas ações podem nos indicar competências a serem consideradas na construção de um perfil dos gestores públicos do esporte e lazer. 
Ao refletirmos a respeito da construção do perfil de competências dos gestores públicos do esporte e lazer, Pintos e Perim (2013), que discutem acerca da responsabilidade social do gestor público de esporte e lazer, indicam-nos alguns fatores que merecem ser considerados. Segundo as autoras, o gestor público do esporte e lazer deve desempenhar seu papel frente à oferta do esporte $\mathrm{e}$ lazer à população, levando em consideração alguns aspectos como:

1) a qualidade da gestão do esporte e lazer frente à necessidade de otimização dos diferentes recursos físicos, materiais, humanos e financeiros disponíveis aos gestores;

2) o desenvolvimento sustentável, uma vez que se deve preservar e dar utilidade social aos recursos existentes;

3) os anseios, as necessidades e as potencialidades dos cidadãos, que fomentem a participação da população nas discussões e concretização de ações;

4) a definição das funções e dos devidos responsáveis para alcançar objetivos, como organizar e desenvolver projetos, programas e adequação de infraestrutura para tais fins;

5) a tentativa de alinhar o domínio dos conhecimentos dos agentes com a realidade, a experimentação e a seleção de atividades pela livre escolha dos cidadãos;

6) a busca pela efetivação de políticas após um processo de análise de escolha de projetos e programas, processo esse desenvolvido em cada região na articulação com as comunidades, estimulando a participação e a organização dos cidadãos frente a construção de projetos e programas para efetivação das políticas;

7) a atuação de modo estratégico, buscando avançar corrigindo as falhas;

8) a clareza dos objetos de modo que justifiquem os gastos e a arrecadação do dinheiro público;

9) o desenvolvimento de políticas que levem em consideração a compreensão do espaço público que requer envolvimento individual, mas também a conscientização das questões coletivas (PINTOS; PERIM, 2013).

Concordamos quando as autoras afirmam que esses fatores são essenciais e podem representar uma frente estratégica no processo de implementação das políticas públicas de esporte e lazer, uma vez que ampliam a capacidade de governança e qualificam os processos de tomada de decisões por parte dos gestores públicos do esporte e lazer. Esses fatores também são importantes quando pensamos nas ações desempenhadas pelos professores, estagiários e profissionais técnicos, pois ambos agentes - gestores, professores, estagiários, técnicos - independente do cargo que assumem, possuem responsabilidades frente à gestão pública do esporte e lazer. As considerações de Marcellino et al. (2007) vão ao encontro desse entendimento quando afirmam que, independentemente da função a ser exercida, o profissional necessita da combinação de algumas 
características como: formação, informação, comportamento e atitude, atualização, imaginação e intuição, criatividade, cooperativismo, dedicação, comunicação e autoformação permanente.

Além dos pontos levantados, Bernabé e Natali (2014) apontam outros aspectos considerados a partir do estudo que analisou a formação e atuação de recreadores públicos do município de Maringá-PR. O princípio da formação política e social ampliada é um dos princípios apontados, pensado a partir da atuação de agentes públicos e que, portanto, pode ser entendido como um ponto importante a ser considerado no decorrer da formação dos agentes. Esse princípio leva em conta o fato dos agentes desenvolverem consciência em relação às questões que perpassam a vida em sociedade, como questões sociais, econômicas, políticas, culturais e demais questões que se encontram articuladas no decorrer do cotidiano dos cidadãos (BERNABÉ; NATALI, 2014).

O princípio das vivências práticas e sociais diversificadas apresenta-se como outro princípio a ser considerado devido à necessidade de se atender diferentes públicos, em diferentes espaços, mediante diferentes contextos, seja em bairros de classes econômicas diferentes, escolas, praças, ruas, dentre outros (BERNABÉ; NATALI, 2014).

Outro ponto considerado é o da troca e compartilhamento das experiências e práticas profissionais que leva em conta a necessidade de reflexão e discussão das ações desenvolvidas entre os agentes que compõem um determinado órgão responsável pelo esporte e lazer nos municípios. Além de outros princípios, como o de reconhecimento e participação nos processos da gestão, e o de democratização do esporte e lazer, princípios voltados à necessidade de abertura à participação popular nos processos de decisão e implementação das políticas públicas (BERNABÉ; NATALI, 2014). A partir desses princípios elencados, destaca-se a importância de se desenvolver processos de formação integral, constante ou continuada, que fundamentem a atuação profissional dos agentes públicos.

Assumindo que a formação dos agentes públicos deve ser pautada em uma fundamentação teórico-prática que integre diferentes saberes, experiências e conhecimentos, bem como pela realização de cursos, participação em palestras, eventos e experiência acumulada em diferentes situações peculiares à gestão do esporte e lazer, buscamos no decorrer desse ensaio discorrer a respeito de características, condições estruturais e competências que, no nosso entender, devem contemplar a formação de gestores, professores, técnicos e estagiários que atuam na gestão pública do esporte e lazer municipal. De modo geral, pautando-nos na literatura que discute sobre as competências de gestores do esporte e lazer, constatamos que as principais competências requeridas a esse cargo são: planejar; tomar decisões; comunicar-se; mobilizar ou controlar recursos humanos e financeiros/orçamentários; e coordenar. 
Quando falamos em competências, características e peculiaridades próprias à atuação dos agentes públicos e que, por esse motivo, entendemos como aspectos relevantes a serem considerados no processo de formação desses agentes, baseando-nos na literatura, chegamos aos seguintes pontos que devem ser considerados: buscar a qualidade da gestão por meio da otimização dos recursos; preservar e dar utilidade aos recursos por meio do desenvolvimento sustentável, ambos pontos ligados ao princípio das vivências e práticas sociais e diversificadas; fomentar a participação popular por meio do princípio da democratização do esporte e do lazer; definir funções e responsabilidades frente aos objetivos propostos; ter domínio dos conhecimentos, técnicas e saberes próprios do esporte e do lazer e saber alinhá-los à realidade da comunidade; buscar a efetivação das políticas; refletir nas ações, buscando corrigir as falhas para avançar por meio do desenvolvimento do princípio das trocas e compartilhamento das experiências e práticas profissionais; desenvolver o princípio da formação política e social e o princípio do reconhecimento e da participação nos processo da gestão ampliada, buscando compreender o espaço social como um espaço público, sabendo tencionar o envolvimento individual do agente com as questões coletivas inerentes à gestão pública.

\section{REFERÊNCIAS}

AMARAL, Cacilda Mendes dos Santos; BASTOS, Flávia da Cunha. O gestor esportivo no Brasil: revisão de publicações no país. Revista Intercontinental de Gestão Desportiva. 2015; 5: 68-78. Disponível em: $\mathrm{http}: / /$ revista.universo.edu.br/index.php?journal=gestaoesportiva\&page $=$ article\&op=view \&path $\% 5 \mathrm{~B} \% 5 \mathrm{D}=1$ 493\&path\%5B \%5D=1317. Acesso em: 03/02/21

AMARAL, Silva Cristina Franco; KIKUCHI, Deise Miki. Política pública de lazer em Suzano/SP: a concepção dos gestores. Licere. 2011; 14: 01-22.DOI: https://doi.org/10.35699/1981-3171.2011.781

ARAÚJO, Silvana Martins; MOTA, Maria Aparecida; SILVA, Marilene Moura dos Santos; CARVALHO, Maria do Socorro. Gestores e agentes sociais de esporte e lazer na Baixada Maranhense: um estudo dos recursos humanos para o Sistema Nacional de Esporte e Lazer. XVI Congresso Brasileiro de Ciências do Esporte e II Congresso Internacional de Ciências do Esporte / Colégio Brasileiro de Ciências do Esporte. Porto Alegre, BR. Porto Alegre; 2007.

BERNABÉ, Andressa Peloi; NATALI, Paula Marçal. Formação e atuação de recreadores: o caso da equipe de recreação e lazer da cidade de Maringá-PR nos anos de 2001 a 2004. Licere. 2014; 17 :

01-19.DOI: https://doi.org/10.35699/1981-3171.2014.620

BOURDIEU, Pierre. A distinção: crítica social do julgamento. Editora Zouk, 2006.

BOURDIEU, Pierre. A Distinção: crítica social do julgamento. Tradução: Daniela Kern e Guilherme F. Teixeira. São Paulo: Edusp; Porto Alegre, RS: Zouk, 2007b.

BOURDIEU, Pierre. Escrito de educação. Editora Vozes, 2 ed, 1999. 
BOURDIEU, Pierre. Escritos de educação. Tradução: Maria Alice Nogueira e Afrânio Catani. 9 ed. Petrópolis, Rio de Janeiro: Vozes, 2007a.

ELIAS, Norbert. Teoria simbólica. Oeiras: Celta, 2002.

FLEURY, Afonso Carlos Correa; FLEURY, Maria Tereza Leme.Estratégias empresariais e formação de competências: um quebra-cabeça caleidoscópico da indústria brasileira. 3 ed. São Paulo: Atlas, 2011.

GALINDO, Alexandre Gomes. Esporte e lazer municipal: reflexões sobre as bases do planejamento e gestão pública. Revista do Plano Diretor Participativo do Município de Santana-AP. 2005; 1: 49-62. Disponível em: https://mid.curitiba.pr.gov.br/2015/00160848.pdf. Acesso em: 03/02/21.

GRUNENNVALDT, José Tarcísio; GRUNENNVALDT, Ana Carrilho Romero; LOPES DA SILVA, João Batista; BEBER, Irene Carrillo Romero. O esporte e lazer no município de Sinop-MT: um estudo de suas manifestações na cidade e no campo (2011). Encontro Anual da Rede Cedes. Brasília, BR. Brasília; 2014.

JAMIESON, Lynn. Competency-Based Approaches to sport Management. Journal of Sport Management, Champaign. 1987; 01: 48-56. DOI: https://doi.org/10.1123/jsm.1.1.48

JOAQUIM, Bárbara Andreia; BATISTA, Paula Maria; CARVALHO, Maria José. Revisão Sistemática sobre o perfil de competências do gestor desportivo. Movimento. 2011; 01; 255-79. DOI:

https://doi.org/10.22456/1982-8918.15104

MARCELLINO, Nelson Carvalho. Lazer e esporte: políticas públicas. Campinas, SP: Autores Associados, 2001.

MARCELLINO, Nelson Carvalho; SAMPAIO, Tânia Mara Vieira Sampaio; CAPI, André Henrique Chabaribery; SILVA, Débora AMachado. Políticas públicas de lazer - formação e desenvolvimento de pessoal: os casos de Campinas e Piracicaba-SP. Curitiba, PR: OPUS, 2007.

MARIN, Elizara Carolina; RIBAS, João Francisco Magno; SILVA, Sabrine Damian; SILVA, Andressa Ferreira. Análise dos protagonistas que facultam as manifestações de esporte e lazer da Região Central do estado do RS. XXI Enarel, 2009; Florianópolis, BR. Florianópolis: 2009.

MAZZEI, Leandro Carlos; BASTOS, Flávia da Cunha (Orgs.) Gestão de esporte no Brasil: desafios e perspectivas. São Paulo: Ícone, 2012.

MENDES, Diego de Sousa; RIBEIRO, Sérgio Dorenski Dantas; MEZZAROBA, Cristiano; SANTOS, Aliomar de Carvalho; ARAGÃO, Paula; GARCIA, Luciana Carolline Pina; OLIVEIRA, Tamires Santos; MENEZES DOS SANTOS, Silvan. Projeto orla: análise preliminar dos equipamentos de esporte e lazer da praia de Atalaia em Aracaju/SE. Congresso Sulbrasileiro de Ciências do Esporte, 2010; Itajaí, BR. UIVALI: Itajaí: 2010.

MENEZES, Vilde Gomes; OLIVEIRA, Aurenéa Maria; SOUZA, Edílson Fernandes. Gestão desportiva e política pública na região metropolitana de Recife. Revista Brasileira de Educação Física e Esporte. 2012; 26: 219-30. DOI: https://doi.org/10.1590/\$1807-55092012000200005

MEZZADRI, Fernando Marinho; STAREPRAVO, Fernando Augusto; BASSO, Daniel; GUIMARÃES, Luisiana; REIS, Robson Privado. Políticas públicas para o esporte e o lazer nas cidades do estado do Paraná. In: MEZZADRI, Fernando Marinho; CAVICHIOLLI, Fernando Renato; SOUZA, Doralice Lange (Orgs.) Esporte e Lazer: subsídios para o desenvolvimento e gestão de políticas públicas. São Paulo: Fontoura; 2006. 
MINTZBERG, Henry. Criando organizações eficazes: estruturas em cinco configurações. São Paulo: Atlas, $2^{\mathrm{a}}$ ed., 2003.

PINTOS, Ana Elenara; PERIM, Gianna L. A responsabilidade social do gestor público do esporte e lazer. In: Tondin G, Vidal JR, Feix E. (Orgs.) Esporte e lazer no Brasil: divisão de responsabilidades entre os entes federativos. XXI Seminário Nacional de Políticas Públicas de Esporte e Lazer; Porto Alegre: Companhia Riograndense de Artes Gráficas; (CORAG), 2013.

SORIANO, Jeane Barcelos; WINTERSTEIN, Pedro José. Limites e desafios para o estudo da intervenção profissional em educação física a partir da noção de competência. Revista Movimento. 2006; 12: 175-195. DOI: https://doi.org/10.22456/1982-8918.2888

TAVARES, Anderson Lopes. As competências dos gestores públicos de esporte [dissertação]. Pedro Leopoldo (MG): Faculdades Integradas de Pedro Leopoldo, Fundação Cultural Dr. Pedro Leopoldo, UNIPEL, 2010.

WERNECK, ChristianneLuce Gomes. Lazer e formação profissional na sociedade atual: repensando os limites, os horizontes e os desafios para a área. Licere. 1998; 01: 47-65.

DOI: https://doi.org/10.35699/1981-3171.1998.1556

ZARIFIAN, Philippe. O modelo da competência: trajetória histórica, desafios atuais e propostas. Tradução: Eric Roland René Heneaut. São Paulo: Senac São Paulo, 2003.

ZARIFIAN, Philippe. Objetivo competência: por uma nova lógica. Tradução: Maria Helena C. V. Trylinski. São Paulo: Atlas, 2001.

\section{NOTAS DE AUTOR}

\section{AGRADECIMENTOS}

Agradecemos os (as) agentes públicos de esporte e lazer do estado do Paraná que participaram da pesquisa, permitindo que a mesma fosse realizada.

Agradecemos também os membros do Grupo de Estudos e Pesquisas em Políticas Públicas de Esporte e Lazer (GEPPOL / DEF / UEM) que colaboraram com o desenvolvimento das coletas e demais pesquisas que contribuíram para o desenvolvimento do presente artigo.

CONTRIBUIÇÃO DE AUTORIA - Não se aplica.

\section{FINANCIAMENTO}

Bolsa de Mestrado - Coordenação de Aperfeiçoamento de Pessoal de Nível Superior (CAPES).

Conselho Nacional de Desenvolvimento Científico e Tecnológico ( $\mathrm{CNPq}$ ), Projeto "Análise dos Agentes Públicos do Sistema Nacional de Esporte", Chamada 91/2013 - L.2, Processo 487407/2013-0.

CONSENTIMENTO DE USO DE IMAGEM - Não se aplica.

\section{APROVAÇÃO DE COMITÊ DE ÉTICA EM PESQUISA}

Informar se teve ou não aprovação do comitê de ética, número de processo e data, anexar o o documento comprobatório como suplementar. Quando a pesquisa não ter necessidade de aprovação em comitê de ética, informar: não se aplica.

CONFLITO DE INTERESSES - Não se aplica. 


\section{LICENÇA DE USO}

Os autores cedem à Motrivivência- ISSN 2175-8042 os direitos exclusivos de primeira publicação, com o trabalho simultaneamente licenciado sob a Licença Creative Commons Attribution Non-Comercial ShareAlike (CC BY-NC SA) 4.0 International. Esta licença permite que terceiros remixem, adaptem e criem a partir do trabalho publicado, desde que para fins não comerciais, atribuindo o devido crédito de autoria e publicação inicial neste periódico desde que adotem a mesma licença, compartilhar igual. Os autores têm autorização para assumir contratos adicionais separadamente, para distribuição não exclusiva da versão do trabalho publicada neste periódico (ex.: publicar em repositório institucional, em site pessoal, publicar uma tradução, ou como capítulo de livro), com reconhecimento de autoria e publicação inicial neste periódico, desde que para fins não comerciais e compartilhar com a mesma licença.

\section{PUBLISHER}

Universidade Federal de Santa Catarina. Programa de Pós-Graduação em Educação Física. LaboMídia - Laboratório e Observatório da Mídia Esportiva. Publicado no Portal de Periódicos UFSC. As ideias expressadas neste artigo são de responsabilidade de seus autores, não representando, necessariamente, a opinião dos editores ou da universidade.

\section{EDITORES}

Mauricio Roberto da Silva, Giovani De Lorenzi Pires, Rogério Santos Pereira.

\section{EDITOR DE SEÇÃO}

Rogério Santos Pereira.

\section{REVISÃO DO MANUSCRITO E METADADOS}

João Caetano Prates Rocha; Keli Barreto.

\section{HISTÓRICO}

Recebido em: 12 de outubro de 2020

Aprovado em: 08 de dezembro de 2020. 